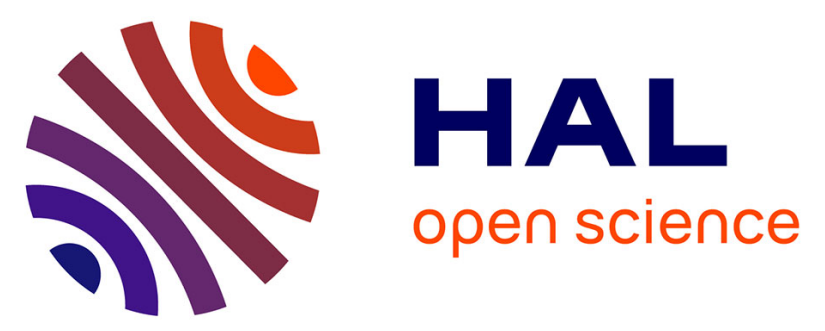

\title{
Curved Polar Dibenzocoronene Esters and Imides Versus their Planar Centrosymmetric Homologs: Photophysical and Optoelectronic Analysis
}

Joachim Vollbrecht, Christian Wiebeler, Harald Bock, Stefan Schumacher, Heinz-Siegfried Kitzerow

\section{To cite this version:}

Joachim Vollbrecht, Christian Wiebeler, Harald Bock, Stefan Schumacher, Heinz-Siegfried Kitzerow. Curved Polar Dibenzocoronene Esters and Imides Versus their Planar Centrosymmetric Homologs: Photophysical and Optoelectronic Analysis. Journal of Physical Chemistry C, 2019, 123 (7), pp.44834492. 10.1021/acs.jpcc.8b10730 . hal-02895133

\section{HAL Id: hal-02895133 https://hal.science/hal-02895133}

Submitted on 9 Jul 2020

HAL is a multi-disciplinary open access archive for the deposit and dissemination of scientific research documents, whether they are published or not. The documents may come from teaching and research institutions in France or abroad, or from public or private research centers.
L'archive ouverte pluridisciplinaire HAL, est destinée au dépôt et à la diffusion de documents scientifiques de niveau recherche, publiés ou non, émanant des établissements d'enseignement et de recherche français ou étrangers, des laboratoires publics ou privés. 


\title{
Curved Polar Dibenzocoronene Esters and
}

\section{Imides Versus their Planar Centrosymmetric}

Homologs: Photophysical and Optoelectronic

\section{Analysis}

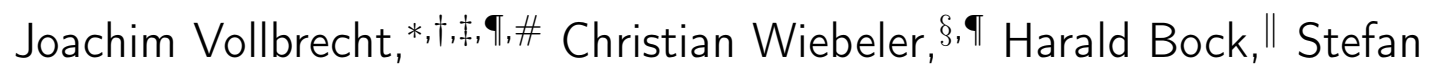

Schumacher, ${ }^{\perp, \ddagger}$ and Heinz-Siegfried Kitzerow ${ }^{\dagger, \ddagger}$

$\dagger$ Department of Chemistry, Physical Chemistry, University of Paderborn, 33098 Paderborn, Germany

$\ddagger$ Center for Optoelectronics and Photonics Paderborn, University of Paderborn, 33098

Paderborn, Germany

IThese authors contributed equally

$\S$ Fritz Haber Center for Molecular Dynamics Research, Institute of Chemistry, The Hebrew University of Jerusalem, Jerusalem 91904, Israel

\|Centre de Recherche Paul Pascal, CNRS, Université Bordeaux, 33600 Pessac, France

$\perp$ Department of Physics, University of Paderborn, 33098 Paderborn, Germany

\#Current address: Center for Polymers \&3 Organic Solids, University of California, Santa

Barbara, CA 93106-5090, USA

E-mail: jvollbrecht@ucsb.edu 


\begin{abstract}
Isomeric columnar liquid crystalline dibenzo $[a, j]$ coronene-tetracarboxylic tetraesters and bisimides that differ only by having either a centrosymmetric bis-peri or a polar bis-ortho substitution pattern, exhibit striking differences in the makeup of their electronic ground and excited states, as well as in their performance as emitters in electroluminescent diodes. Quantum chemical calculations show that the key molecular orbitals consist essentially of perylene-like ones responsible for the longest-wavelength absorptions, and coronene-like ones responsible for the very intense shorter-wavelength absorptions, with modifications in particular for the ortho-imide due to its pronounced deviation from planarity. Additionally, the ortho-imide and ortho-ester, which tend to a slipped-stacked configuration within their columns due to their non-planarity, strongly outperform their peri-counterparts as emitters in organic light emitting diodes.
\end{abstract}

\title{
Introduction
}

For several decades, organic semiconductors (OSC) and organic electronics (OE) have been in the focus of research. ${ }^{1,2}$ Considerable advances have been made, since the first applications in organic light emitting diodes (OLED), ${ }^{3}$ organic photovoltaics (OPV), ${ }^{4}$ organic field effect transistors (OFET), ${ }^{5,6}$ flexible electronics, ${ }^{7}$ or sensors ${ }^{8}$ were reported. One of the most promising aspects of OE-research is the potential use of roll-to-roll processes that would allow large scale production at low costs. ${ }^{9}$ OLEDs in particular have had some commercial success in display applications and are believed to also have an impact in the lighting industry as planar light sources. ${ }^{10}$

The ongoing investigation of new materials that could be applied in OLEDs is a necessary prerequisite for further advances in this field. One example is the expansive group of perylene derivatives. ${ }^{11,12}$ The effects of modified side chains, ${ }^{13}$ functional groups, ${ }^{14}$ and the addition of hetero-atoms ${ }^{15}$ have been studied in recent years. But also the role of the aromatic core has been subject of in-depth research. ${ }^{16-21}$ In addition, some perylene-derivatives have liquid 
crystalline (LC) properties, which can be generally advantageous, since the self-ordering of the molecules in thin films can improve the charge carrier mobility. ${ }^{22}$ Another promising aspect of LC-OSCs is the possibility to remove defects that occur during the manufacturing process of thin films by heating these films into their LC-phase and slowly cooling them down again, which is commonly referred to as self-healing. ${ }^{23}$ In particular, OSCs with LC properties have been investigated for OLED-, ${ }^{24-27}$ OPV-, ${ }^{28,29}$ and OFET-applications, ${ }^{30}$ among other examples. ${ }^{31-33}$

Here we present the detailed photophysical analysis, and study the applicability as emitter materials in OLEDs of four different types of dibenzo[ $a, j]$ coronene-tetracarboxylic alkyl esters and imides with either a centrosymmetric bis-peri $(\mathbf{1} \& \mathbf{3})$ or a polar bis-ortho $(\mathbf{2}$ \& 4) substitution pattern (Fig. 1). ${ }^{34}$ The experimentally obtained absorption spectra were compared to quantum chemical calculations based on density functional theory (DFT). The electronic transitions that are of special interest in spectroscopy were further analyzed. The optoelectronic properties of the manufactured OLEDs were characterized and the suitability of thermal evaporation in a vacuum as deposition method for these compounds was investigated and will be discussed in the section Optoelectronic Characterization of this article. 


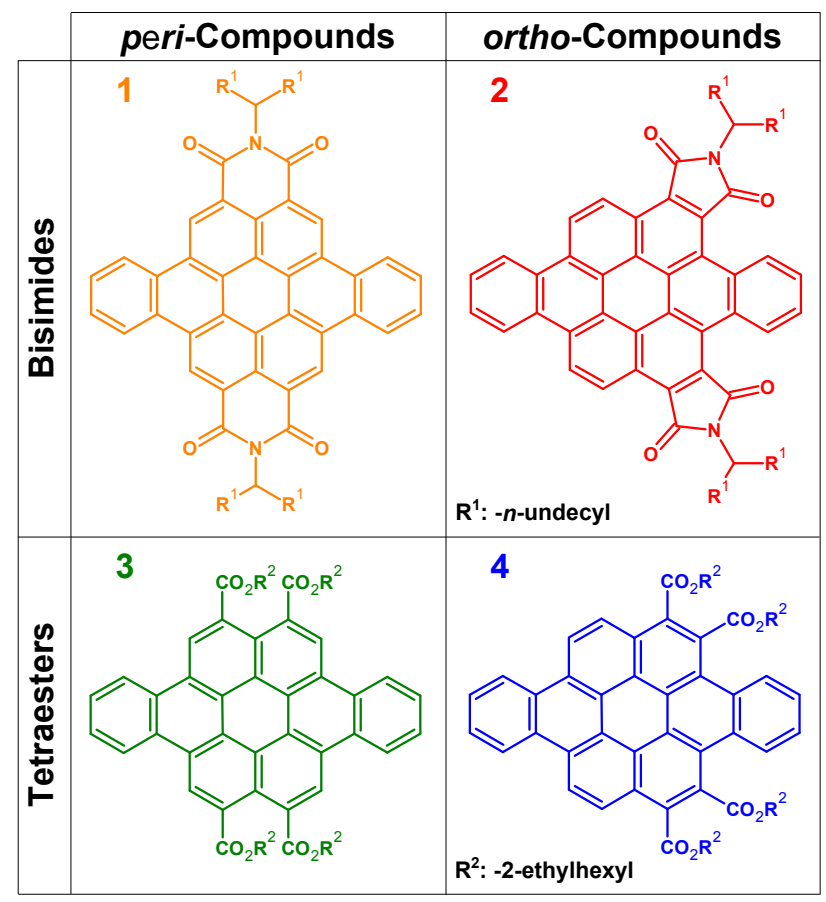

Figure 1: Chemical structures of the investigated emitter materials.

\section{Methods}

Thin films were fabricated via two different methods, namely thermal evaporation in a vacuum $\left(p<10^{-6} \operatorname{mbar} ; T=200-300{ }^{\circ} \mathrm{C}\right)$ or spin-coating of solutions. The four different tested emitter materials can all be dissolved in $\mathrm{CHCl}_{3}$ and are all suitable for thermal evaporation in a vacuum, although compound $\mathbf{3}$ shows some new bands in the absorption after the evaporation process, which could indicate chemical degradation (Fig. S1 in the SI). To study the spectroscopic properties of the thin films, glass slides were used as substrates. These slides were thoroughly cleaned and sonicated in de-ionized water with detergent, rinsed, sonicated once more in isopropyl-alcohol, and stored in an oven at $T=70{ }^{\circ} \mathrm{C}$. The slides were treated in an ozone plasma prior to the deposition process. Subsequently, thin films ranging from $d=30-45 \mathrm{~nm}$ were deposited on these glass substrates. Absorption and photoluminescence (PL) spectra were measured for these thin films to assess any significant differences between solutions and thin films. Once these thin films were analyzed, they were dissolved 
in $\mathrm{CHCl}_{3}$ and investigated again to observe, whether the deposition process changed the properties of the compounds (Fig. S1).

Instead of glass slides, glass substrates coated with a layer of indium tin oxide (ITO) were used, when OLEDs were manufactured. The ITO functioned as a transparent anode. Up to 36 OLEDs were fabricated on one substrate at once due to a matrix-like arrangement of the anodes and cathodes. ${ }^{35}$ A pattern of up to six parallel ITO stripes was etched into the substrates with Zn-powder and an HCl-solution; the areas that would later function as anode were masked with scotch tape during the etching process. Subsequently, the etched ITO substrates were cleaned with detergent solution and annealed at $T=250{ }^{\circ} \mathrm{C}$ over $24 \mathrm{~h}$ to increase the conductivity of the ITO. These ITO substrates were then cleaned similarly to the glass slides and also treated in an ozone plasma. As first organic layer, commercially available poly(3,4-ethylenedioxythiophene)-poly(styrenesulfonate) (PEDOT:PSS, $d=140-150 \mathrm{~nm}$ ) was spin-coated on top of the ITO from an aequous solution to serve as hole injection layer and to reduce the surface roughness. These spin-coated ITO substrates were then annealed for $1 \mathrm{~h}$ at $T=60{ }^{\circ} \mathrm{C}$ to remove any traces of solvent. As second organic layer, commercially available $N, N^{\prime}$-bis(3-methylphenyl)- $N, N^{\prime}$-diphenylbenzidine (TPD; $\left.d=15 \mathrm{~nm}\right)$ was evaporated on top of the PEDOT:PSS-layer. The TPD-layer functioned as a holetransporting layer. The third organic layer consisted of one of the four different emitter materials $(d=30 \mathrm{~nm})$, respectively, which was also thermally evaporated. To finish the OLED, up to six parallel stripes of aluminum were thermally evaporated on top of the organic layers, oriented orthogonally to the ITO stripes, thus forming the matrix pattern mentioned earlier. Due to the width of the ITO and aluminum stripes, OLEDs with an active area of $A=0.6 \cdot 0.6 \mathrm{~cm}^{2}$ were formed.

Molecular structures of the four investigated compounds were created with GaussView. ${ }^{36}$ For computational reasons, the aliphatic side chains were replaced by hydrogen atoms, which is expected to have a negligible impact on the investigated properties. Our quantum chemical calculations are along the lines of our previous publications. ${ }^{18,37}$ The Gaussian 09 software 
suite was used for all calculations. ${ }^{38}$ They are based on density functional theory (DFT) and the PBE0 hybrid functional was employed together with different Pople-style basis sets as explained in more detail below. ${ }^{39-41}$ For initial structure optimizations, the 6-311G(d,p) basis set was used and the optimized structures were verified to be minima by vibrational frequency calculations with the same method. Subsequently, single point calculations with the $6-311+G(d, p)$ basis set were performed to determine orbital energies and excited states. In particular for the former, the addition of diffuse functions was found to be important, which was already noted in previous studies. ${ }^{18,42}$ For the latter, the first 20 excited states were determined covering at least all transitions down to $285 \mathrm{~nm}$. To obtain spectra, each transition was convoluted with a Gaussian function with a broadening of ca. $0.17 \mathrm{eV}$ full width at half maximum. To understand the nature of the electronic transitions that are responsible for light absorption, natural transition orbitals (NTOs) were calculated with the TheoDORE package and the results were visualized using Jmol. ${ }^{43-46}$

The ground $\left(S_{0}\right)$ and first two excited states $\left(S_{1}\right.$ and $\left.S_{2}\right)$ of compound 1 were considered for the vibronic calculations taking into account Franck-Condon and Herzberg-Teller terms. ${ }^{47}$ The 6-31G(d) basis set was used to reduce the computational demands in particular for the excited state optimizations and corresponding frequency calculations. A spectrum progression of $99.98 \%$ towards the analytic limit was obtained by employing 8 classes and an integral threshold of $10^{10}$. The spectrum was then calculated by convoluting each vibronic transition with a Gaussian function using a half width at half maximum of $300 \mathrm{~cm}^{-1}$. 


\section{Absorption Spectroscopy and Electronic Structure}

\section{Quantum Chemical Calculations}
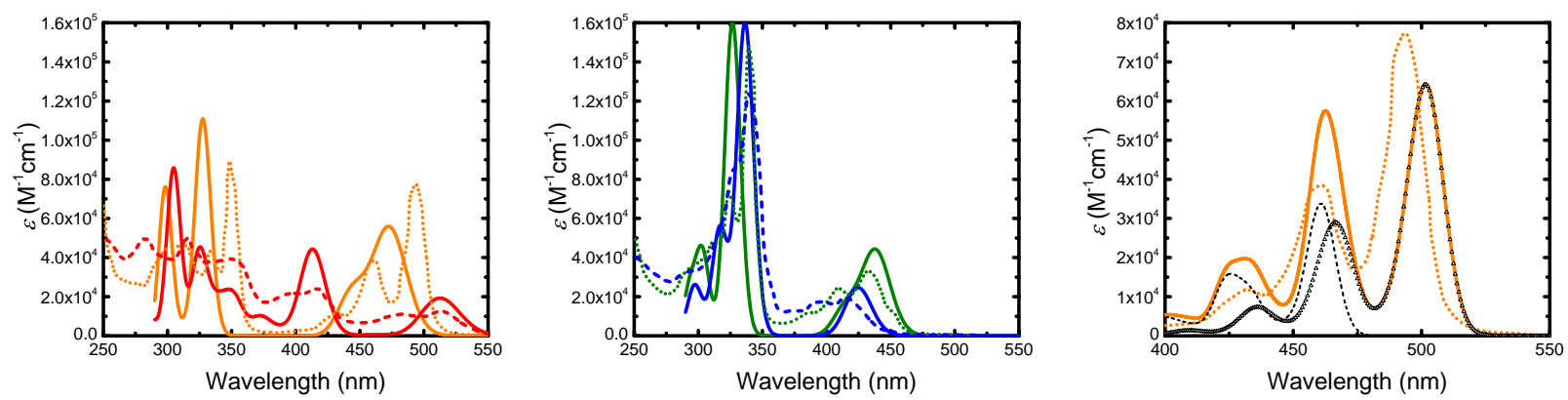

Figure 2: Absorption of the imides $\left(\mathbf{1}, \mathbf{2}\right.$; left) and esters $\left(\mathbf{3}, \mathbf{4}\right.$; middle) in a dilute $\mathrm{CHCl}_{3^{-}}$ solution (1, 3: dots; 2, 4: dashes) and absorption calculated via DFT (solid lines in corresponding color). The measured (orange dots) and calculated (orange line) vibronic absorption spectra for compound $\mathbf{1}$ are displayed in the right panel. The contributions of the $\mathrm{S}_{1}$ (open triangles) and $\mathrm{S}_{2}$ (black dashes) transitions are depicted individually as well.

Comparing the calculated absorption spectra with the previously published measurements, ${ }^{34}$ it can be seen that the experimentally found trends can be reproduced: (i) the lowest energy absorption bands of the imides are red shifted relative to the esters; (ii) For the imides, a marked red shift is found when going from compound 1 to 2; (iii) For the esters, a shift in the opposite direction, i. e. a blue shift, is obtained going from 3 to 4 . However, this shift is not as pronounced as for the imides. Our calculations yield nearly the same shifts as the measurements.

We note that for the simulation of the fine structure of these absorption bands, vibronic effects have to be taken into account. This is in particular the case for compound $\mathbf{1}$, where also the largest mismatch for the positions of the calculated and measured lowest energy absorption maxima is found. Thus, we performed vibronic calculations for the lowest two excited states (Fig. 2, right panel). First of all, it can be seen that the coupling between the electronic and vibrational degrees of freedom leads to a red shift in the lowest energy absorption maximum. Therefore, a better agreement with the measurements is found, when 
the vibronic effects are taken into account. Additionally, the fine structure of the measured spectra can be reproduced indicating that the first three lowest energy absorption peaks are not only caused by the vibronic progression of $\mathrm{S}_{1}$, but also by contributions of the vibronic absorption of $\mathrm{S}_{2}$. This is clearly visible in the spectra for the individual excited states of Fig. 2 (right panel).

Furthermore, our quantum chemical calculations give insights into the nature of the excitations responsible for light absorption. For this purpose, the canonical molecular orbitals can be transformed into natural transition orbitals (NTOs) yielding a minimum number of single-particle orbitals to describe the electronic transitions of interest. ${ }^{43}$ For the investigated molecules, three excited electronic states are of particular interest: $\mathrm{S}_{1}, \mathrm{~S}_{2}$ and the excited state that is causing the highest absorption maximum of each compound in the range between 300 to $350 \mathrm{~nm}$. An overview of these states is given in Tab. 1.

Table 1: Excitation energies in $\mathrm{eV}$ and $\mathrm{nm}$ as well as oscillator strength (Osc. Str.) for the four compounds 1-4. Shown are the corresponding values for states $S_{1}, S_{2}$ and the brightest one in the range between 300 to $350 \mathrm{~nm}$.

\begin{tabular}{c|ccc|ccc|ccc}
\hline & \multicolumn{3}{|c}{$\mathrm{S}_{1}$} & \multicolumn{3}{c}{$\mathrm{S}_{2}$} & \multicolumn{3}{c}{ "Coronene-like" } \\
\hline & $\Delta E / \mathrm{eV}$ & $\lambda / \mathrm{nm}$ & Osc. Str. & $\Delta E / \mathrm{eV}$ & $\lambda / \mathrm{nm}$ & Osc. Str. & $\Delta E / \mathrm{eV}$ & $\lambda / \mathrm{nm}$ & Osc. Str. \\
\hline $\mathbf{1}$ & 2.62 & 473 & 0.336 & 2.79 & 445 & 0.145 & 3.79 & 328 & 0.684 \\
2 & 2.42 & 513 & 0.119 & 2.69 & 460 & 0.004 & 4.07 & 305 & 0.442 \\
3 & 2.83 & 438 & 0.265 & 2.98 & 415 & 0.094 & 3.80 & 327 & 0.983 \\
4 & 2.92 & 425 & 0.152 & 3.04 & 408 & 0.001 & 3.69 & 336 & 0.987 \\
\hline
\end{tabular}




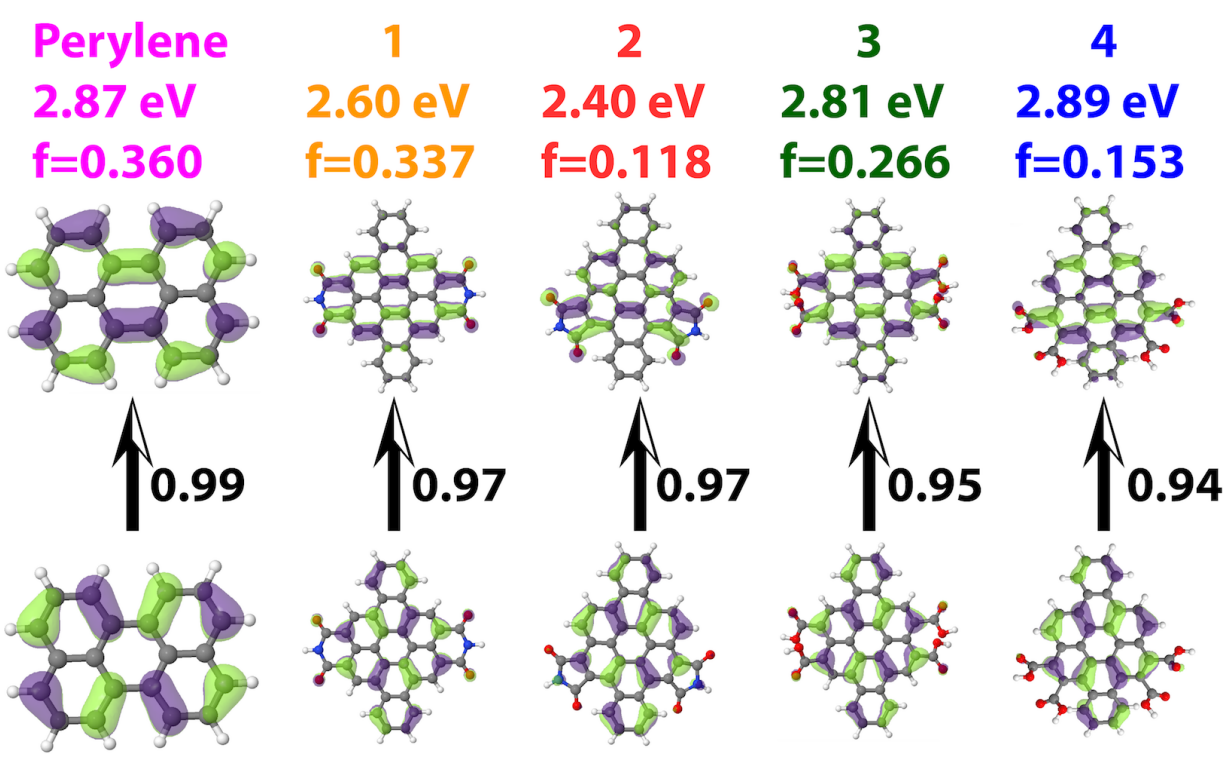

Figure 3: Natural transition orbitals (NTOs) for perylene and compounds 1-4. Given are the excitation energies and oscillator strengths for the first excited state along with the NTOs involved in the electronic transitions and their weights.

For each compound, the first excited electronic state is the origin of the lowest energy absorption maximum and the excitation is dominated by one pair of NTOs. As shown in Fig. 3, these NTOs are similar to the ones from perylene confirming the assignment of the lowest energy absorption as mainly "perylene-like". ${ }^{34}$ The more pronounced differences in NTOs between the investigated compounds and perylene are found for $\mathbf{2}$ and $\mathbf{4}$. This is caused by the significantly bent cores of these two compounds, whereas compounds 1 and 3 are nearly as planar as perylene. An analysis of the bending in more quantitative terms is given in the SI. The differences in the core structures are exemplified by the depiction of the imides 1 and $\mathbf{2}$ in Fig. 4 and of the esters $\mathbf{3}$ and $\mathbf{4}$ in Fig. S6.

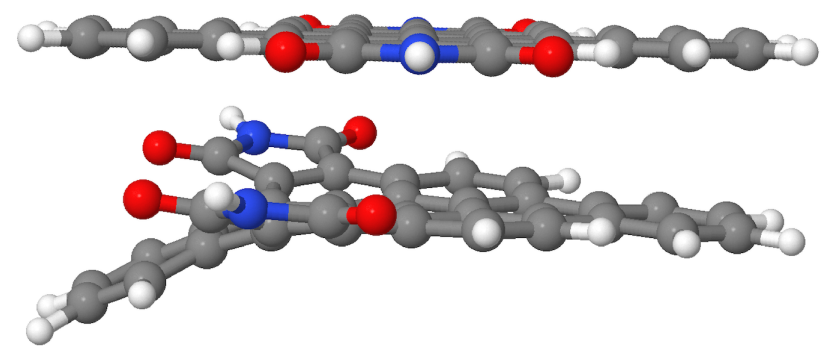

Figure 4: Side view of the molecular structures for the imides $\mathbf{1}$ (upper part) and $\mathbf{2}$ (lower part). 
The $\mathrm{S}_{2}$ state is causing the shoulder in the lowest energy absorption band for the perisubstituted compounds in case of the calculated absorption spectra, whereas the state that is the origin of the highest absorption maximum of each compound in the range between 300 to $350 \mathrm{~nm}$ is considered to be "coronene-like". ${ }^{34}$ As can be seen in Table 1, the transition to $\mathrm{S}_{2}$ exhibits only significant oscillator strengths in case of the peri-substituted compounds 1 and $\mathbf{3}$, whereas it is virtually dark for the ortho-substituted molecules $\mathbf{2}$ and $\mathbf{4}$. In contrast to this, the oscillator strengths for the states responsible for the "coronene-like" absorption are more similar for the esters $\mathbf{1}$ and $\mathbf{2}$ on the one hand and the imides $\mathbf{3}$ and $\mathbf{4}$ on the other.

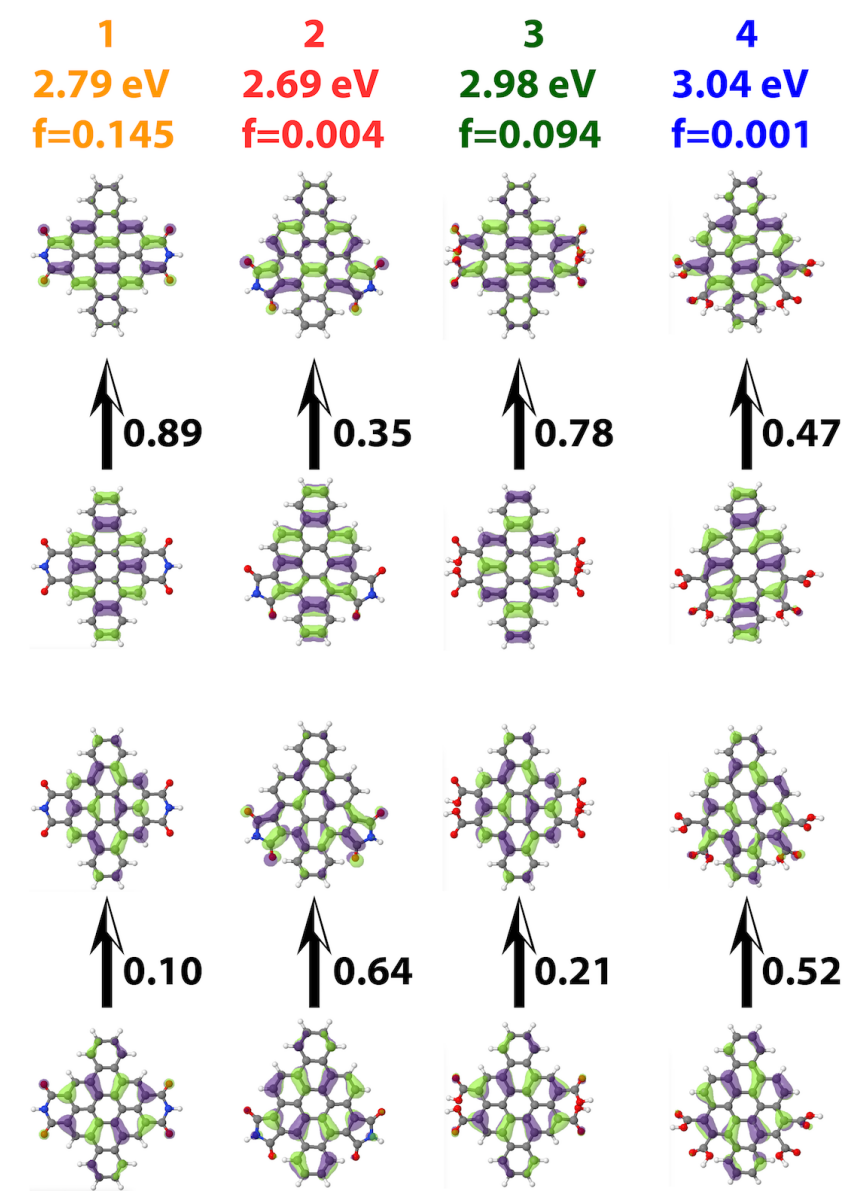

Figure 5: Natural transition orbitals (NTOs) for compounds 1-4. Given are the excitation energies and oscillator strengths for the $\mathrm{S}_{2}$ state along with the NTO pairs involved in these electronic transitions and their weights.

As shown in Fig. 5, excitation into the $\mathrm{S}_{2}$ state is dominated by two pairs of NTOs. Overall, the involved NTOs and also their weights are similar for the peri-substituted compounds 
$\mathbf{1}$ and $\mathbf{3}$, whereas the differences are larger with respect to $\mathbf{2}$ and $\mathbf{4}$. Going from perito ortho-substitution, we find, first of all, that the NTO pair contributing the most has changed and that the mixing of the two pairs is more pronounced. Furthermore, also the shape of the NTOs is slightly different, in particular in case of the upper NTO pairs for the orbitals to where the electron is excited. These NTOs are oriented along the horizontal axis, exhibit strong contributions at the substituents and therefore are influenced the most by the substitution pattern.

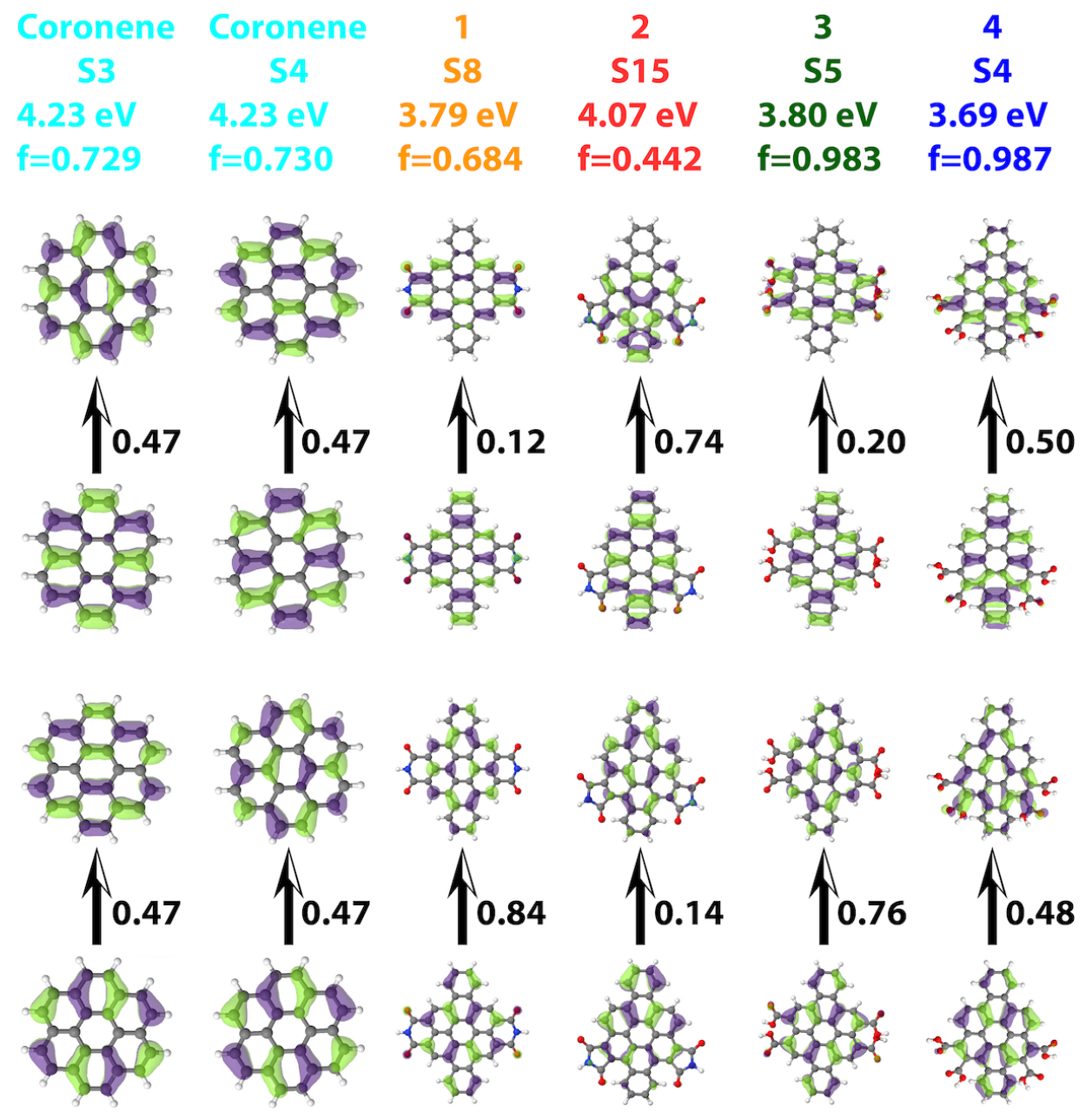

Figure 6: Natural transition orbitals (NTOs) for coronene and compounds 1-4. Given are the excited states, excitation energies and oscillator strengths for the first two bright states in coronene and the brightest states of compounds 1-4 in the spectral range between 300 and $350 \mathrm{~nm}$. In addition, the NTOs involved in the electronic transitions and their weights are shown. 
To assess the nature of the transitions underlying the "coronene-like" absorption, first excited state calculations for coronene were performed. We find that the first two transitions are dark and that the $\mathrm{S}_{3}$ and $\mathrm{S}_{4}$ states are degenerate having the same energy and oscillator strength. Both transitions are composed of two pairs of NTOs that are different, but they share the same four NTOs. Substitution lifts the degeneracy leading for each compound to one electronic transition that exhibits by far the highest oscillator strengths among all 20 excited states calculated. These transitions are depicted in Fig. 6. Overall, the pairs resemble the NTOs of the coronene $\mathrm{S}_{4}$ state and are arranged in a way to facilitate comparison. However, the differences in the orbitals of each class are now more pronounced, in particular in case of compound 2. Similar to the findings of the analysis for the $S_{2}$ state above, the pair with the highest contribution depends on the substitution pattern. Furthermore these pairs are similar to the ones for the $\mathrm{S}_{2}$ state, but their weights are interchanged, i.e. the pair with the higher weight for $\mathrm{S}_{2}$ contributes with a lower weight to the "coronene-like" transition. 


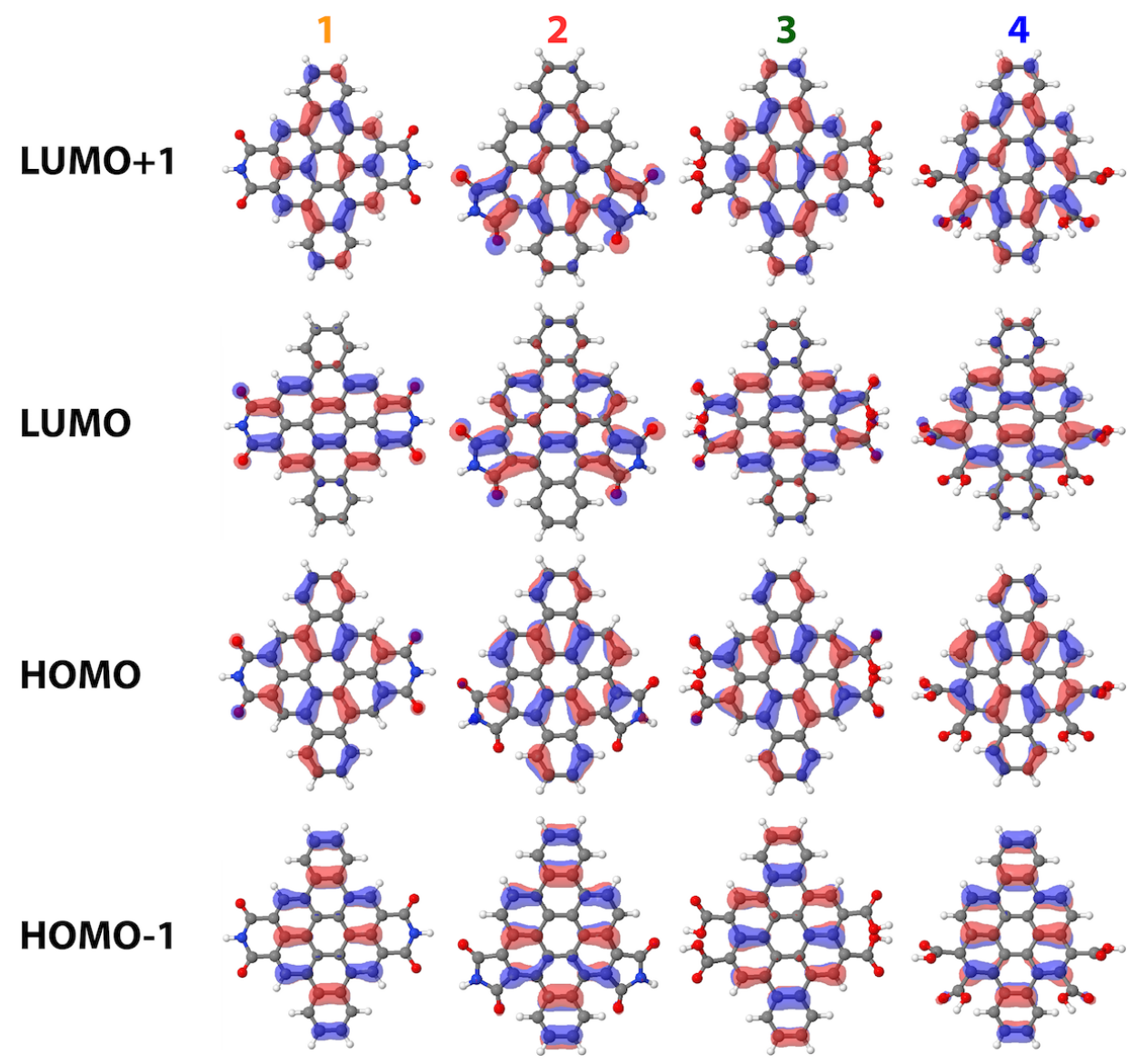

Figure 7: Depiction of the four frontier molecular orbitals, i.e. the highest (HOMO) and second highest (HOMO-1) as well as the lowest (LUMO) and second lowest $(\mathrm{LUMO}+1)$ unoccupied MOs, for compounds 1-4, which are contributing the most to the investigated electronic transitions.

Motivated by the similarity between different NTOs, we have also looked at the molecular orbitals (MO) that are contributing to the analyzed transitions, see Fig. 7. The $\mathrm{S}_{1}$ state is dominated by a transition from the highest occupied MO (HOMO) to the lowest unoccupied MO (LUMO). The pairs for the $\mathrm{S}_{2}$ and "coronene-like" states are in general dominated by transitions between the two highest HOMOs and the two lowest LUMOs, which are similar in shape compared with the corresponding NTOs. These pairs are transitions from HOMO-1 to LUMO and HOMO to LUMO+1. The only exception is found for the "coronene-like" transition of compound $\mathbf{2}$, where the pairs with the highest weights are HOMO-1 to $\mathrm{LUMO}+2$ and $\mathrm{HOMO}$ to $\mathrm{LUMO}+3$. 
We find that the energy of the lowest unoccupied molecular orbital (LUMO) increases starting with $\mathbf{1}(-3.49 \mathrm{eV})$, followed by $\mathbf{2}(-3.22 \mathrm{eV}), \mathbf{3}(-2.96 \mathrm{eV})$ and $\mathbf{4}(-2.64 \mathrm{eV})$. So the experimentally found trend can be reproduced qualitatively, but the changes are overemphasized. Regarding the energy of the highest occupied molecular orbital (HOMO), we observe an increase starting with $\mathbf{1}(-6.56 \mathrm{eV})$, followed by $\mathbf{3}(-6.31 \mathrm{eV}), \mathbf{2}(-6.22 \mathrm{eV})$, and

$4(-6.11 \mathrm{eV})$. With respect to the energy levels determined experimentally, we first note an offset of $c a .-0.4 \mathrm{eV}$ and again the changes going from peri- to ortho-substitution are overemphasized. In this case, this even leads to a slightly different ordering, as compounds $\mathbf{2}$ and $\mathbf{3}$ are now arranged the other way around.

Overall, our quantum chemical calculations are able to reproduce the main findings in the comparison of the four different compounds regarding absorption and energies of the frontier molecular orbitals. In addition they give insights into the nature of the electronic states that are responsible for visible light absorption.

\section{Thin Film Spectra}

As was mentioned earlier, all four compounds can be thermally evaporated in a vacuum at temperatures of $T=200-300{ }^{\circ} \mathrm{C}$. In particular, the imides tend to require higher sublimation temperatures, when compared to their ester counterparts. Moreover, the compounds with a peri-substitution pattern exhibit higher sublimation temperatures than the ortho-substituted compounds. The values of the sublimation temperature $T_{\text {subl }}$ are shown in Table 2 and in Fig. S3, which also depicts the phase transitions reported for the investigated materials. ${ }^{34}$

Comparing the absorption spectra of compounds 1-4 dissolved in $\mathrm{CHCl}_{3}$ with the absorption spectra of the respective thin films is one way to test, whether the evaporation process degrades the emitter materials. While some minor differences between solutions and thin films are expected, no completely new peaks should appear. To further investigate, the ma- 
terial forming the thin films was dissolved in $\mathrm{CHCl}_{3}$ once more. There are no significant differences in the spectra between the pristine and post-evaporation solutions, with the only exception being compound 3 . In the case of compound 3 , a new peak at $\lambda \approx 490 \mathrm{~nm}$ can be observed (Fig. S1), which could indicate some form of chemical degradation, such as anhydride formation. This type of degradation was reported for a tetraester with a similar molecular structure in an earlier study, and quantum chemical calculations performed in this study support the hypothesis of anhydride formation (Fig. S7). ${ }^{35}$
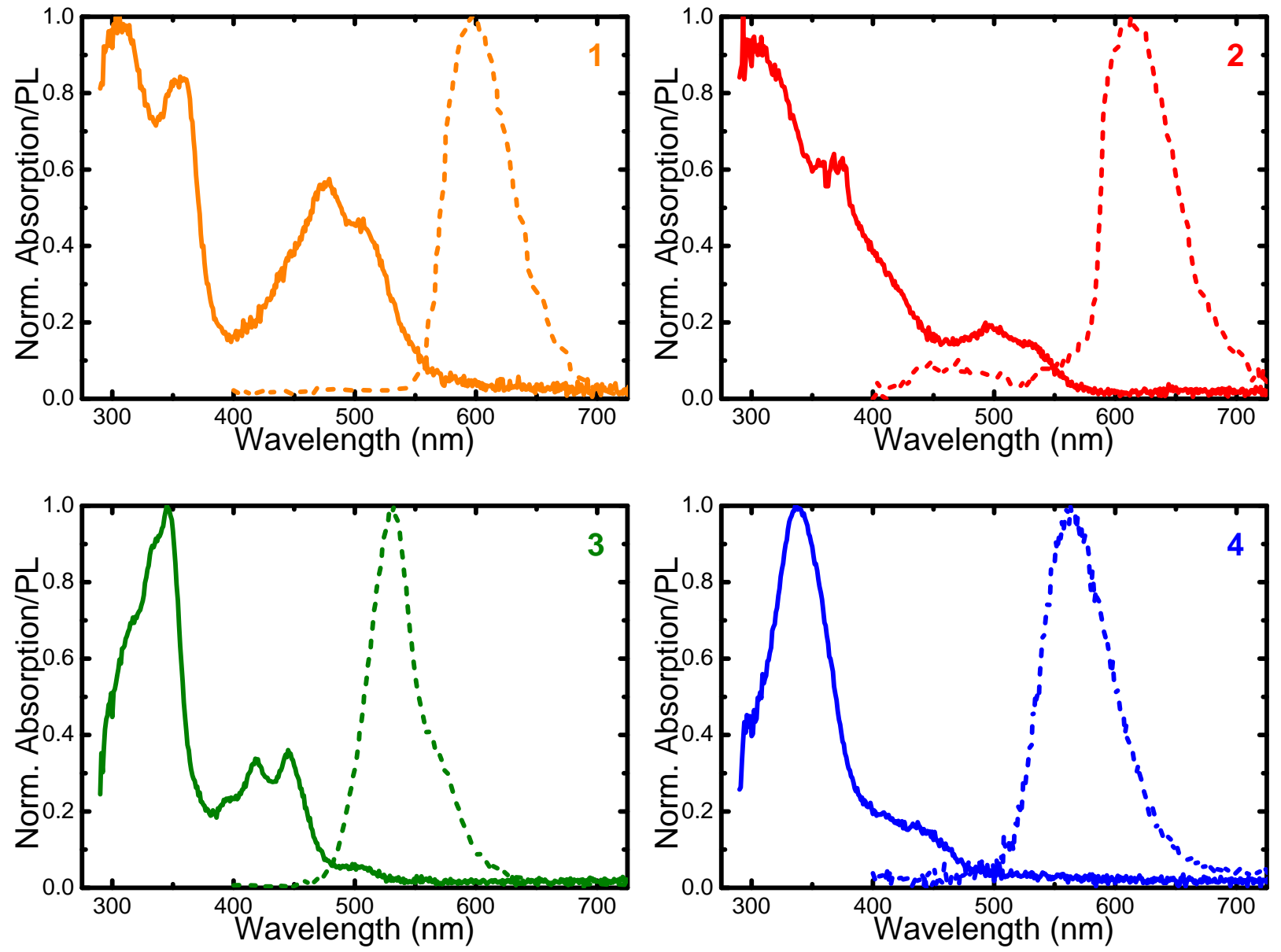

Figure 8: Normalized absorption (solid lines) and PL (dashes) spectra of thin films thermally evaporated in a vacuum of the studied compounds (thickness: $\mathbf{1}, \mathbf{2}=30 \mathrm{~nm} ; \mathbf{3}=38 \mathrm{~nm} ; \mathbf{4}$ $=44 \mathrm{~nm}$ ). The compounds were evaporated at a pressure of $p<10^{-6}$ mbar. The spectral red shifts and sublimation temperatures are listed in Table 2.

Absorption and PL spectra were measured to investigate any significant differences be- 
tween solutions and thin films (Fig. 8, S1, and S2). The absorption spectra of the thin films show spectral broadening when compared to the spectra of the corresponding solutions. However, neither a blue nor red shift between solution and thin film absorption spectra can be observed. This indicates a lack of any significant aggregation that would change the absorption of the thin films, such as the formation of J- or H-aggregates. ${ }^{37,48}$

A spectral shift of $\Delta \lambda \approx 90-125 \mathrm{~nm}$ between the low energy peak of the absorption $\left(\mathrm{S}_{1}\right)$ and the maximum of the PL spectra of the thin films can be reported (Fig. 8 and Table 2). This shift can be explained by the formation of excimers (excited dimer), an often observed phenomenon for this class of compounds. ${ }^{37,48}$ Interestingly, the magnitude of the shift correlates well with the reported intra-columnar stacking distance $d$, where smaller distances result in more pronounced spectral shifts. ${ }^{34,37}$ In particular, only compound $\mathbf{3}$ exhibits a smaller shift $\left(\Delta \lambda_{\mathbf{3}}=87 \mathrm{~nm}\right)$ in comparison to the other compounds $\left(\Delta \lambda_{\mathbf{1 , 2}, \mathbf{4}} \approx 120 \mathrm{~nm}\right)$. At the same time, an intra-columnar distance of $d_{\mathbf{3}}=0.38 \mathrm{~nm}$ was reported for compound $\mathbf{3}$, a higher value than for all the other compounds $\left(d_{\mathbf{1 , 2 , 4}}=0.35 \mathrm{~nm}\right)$ (Table 2$) .{ }^{34}$

Table 2: Spectroscopic data related to the absorption and photoluminescence of thin films. The sublimation temperatures $T_{\text {subl }}$ at pressures $p<10^{-6}$ mbar and intra-columnar stacking distances $d$ are also listed. ${ }^{34}$

\begin{tabular}{c|c|c|c|c|c}
\hline & $\lambda_{\mathrm{S} 1} / \mathrm{nm}$ & $\lambda_{\mathrm{PL}, \max } / \mathrm{nm}$ & $\Delta \lambda / \mathrm{nm}$ & $T_{\text {subl }} /{ }^{\circ} \mathrm{C}$ & $d / \mathrm{nm}$ \\
\hline $\mathbf{1}$ & 479 & 595 & 116 & 295 & 0.35 \\
2 & 498 & 613 & 115 & 265 & 0.35 \\
3 & 445 & 532 & 87 & 210 & 0.38 \\
$\mathbf{4}$ & 438 & 563 & 125 & 200 & 0.35 \\
\hline
\end{tabular}

\section{Optoelectronic Characterization}

The electroluminescence (EL) spectra of the OLEDs with compounds 1-4 as emitter layers are displayed in Fig. 9. As depicted in Fig. S2, the EL spectra of the OLEDs correlate well with the PL spectra of the respective thin films. This observation is common for perylene- and coronene-like materials and generally indicates that the same spectral pathway 
is responsible for EL and PL. ${ }^{18}$

Compared to the PL spectra of the four compounds dissolved in $\mathrm{CHCl}_{3}$, the EL spectra are red shifted, which should also be caused by excimers. While the imide-solutions (1 \& 2) have different peaks in the solution PL, the imide-OLEDs both show an EL peak at $\lambda_{\max } \approx 590 \mathrm{~nm}$. In contrast, both ester-solutions ( $3 \& 4$ ) show similar peaks in their respective PL spectra at about $\lambda_{\max } \approx 455 \mathrm{~nm}$, while the ester-OLEDs have different peaks in the EL spectra (Table 3 and Fig. S2). In comparison, the imides are more red shifted in their emission than the esters, which is a trend that can be observed for other imide and ester emitters with the same aromatic cores. ${ }^{18}$ The EL and solution PL spectra were used to calculate the color coordinates $x$ and $y$. No color coordinates for the thin film PL spectra were calculated, as these spectra are very similar to the EL spectra of the respective OLEDs. The calculated color coordinates are displayed in a chromaticity diagram (Fig. 9) and in Table 3. The inset of the chromaticity diagram shows photographic images of the working OLEDs. 

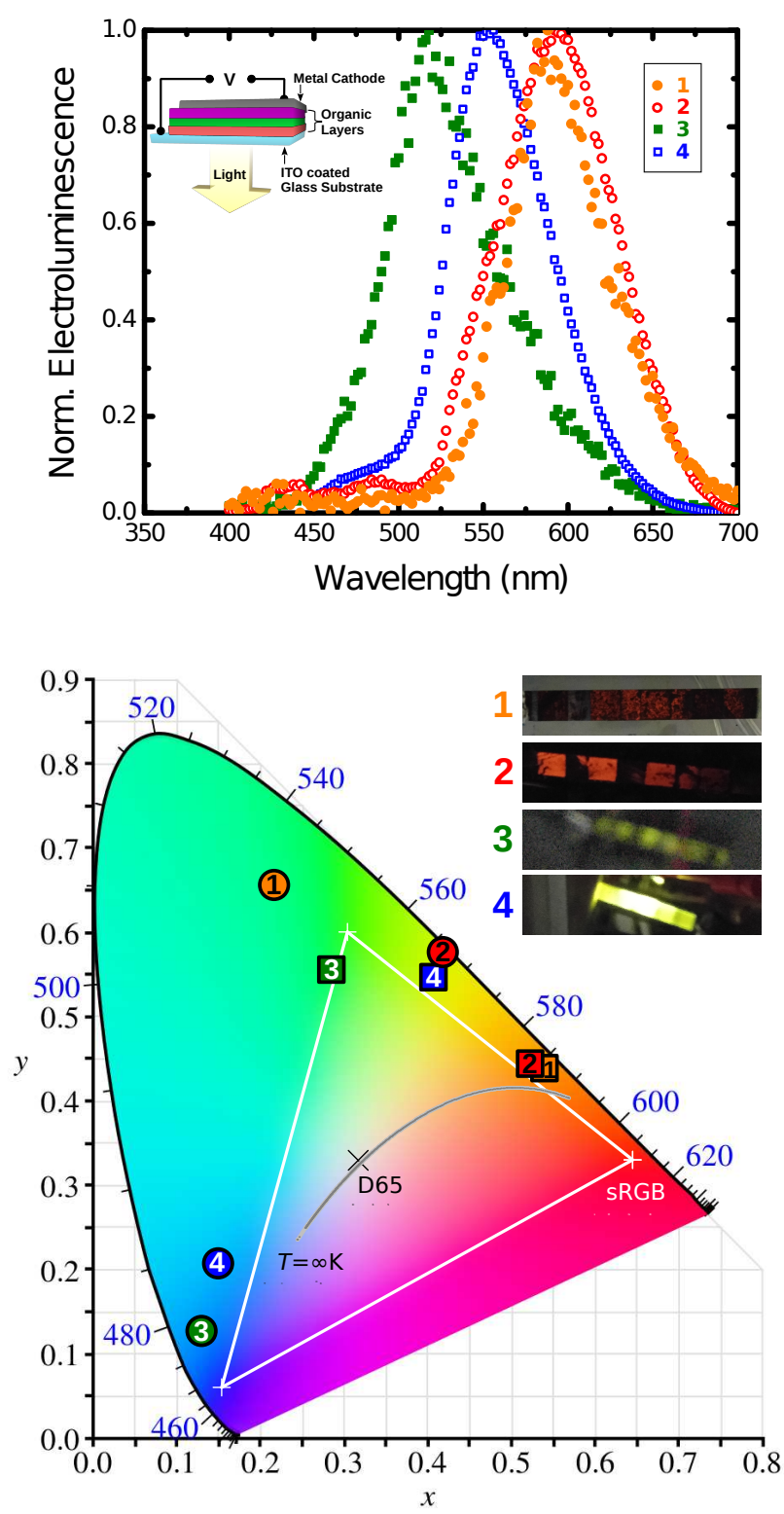

Figure 9: Normalized electroluminescence (EL) of the tested OLEDs and chromaticity diagram of the photoluminescence $(\mathrm{PL})$ of $\mathrm{CHCl}_{3}$-solutions (circles) and electroluminescence (EL) of OLEDs (squares). The insets show the OLED architecture and photographs of working devices, respectively. The thin film PL was omitted in the chromaticity diagram for clarity. 
Table 3: Maximum wavelengths, full widths at half maximum and CIE coordinates of PL- and EL-spectra.

\begin{tabular}{c||cccc|cc|cccc}
\hline \multicolumn{1}{l||}{} & \multicolumn{4}{c}{ Solution PL } & \multicolumn{1}{c}{ Thin Film PL } & \multicolumn{4}{c}{ OLED EL } \\
\hline & $\frac{\lambda_{\max }}{\mathrm{nm}}$ & $\frac{\mathrm{FWHM} M}{\mathrm{~nm}}$ & $x$ & $y$ & $\frac{\lambda_{\max }}{\mathrm{nm}}$ & $\frac{\mathrm{FWHM}}{\mathrm{nm}}$ & $\frac{\lambda_{\max }}{\mathrm{nm}}$ & $\frac{\mathrm{FWHM}}{\mathrm{nm}}$ & $x$ & $y$ \\
\hline 1 & 502 & 20 & 0.21 & 0.66 & 595 & 64 & 588 & 61 & 0.54 & 0.44 \\
2 & 541 & 62 & 0.41 & 0.58 & 613 & 70 & 592 & 85 & 0.52 & 0.44 \\
3 & 456 & 17 & 0.13 & 0.13 & 532 & 46 & 518 & 69 & 0.28 & 0.56 \\
4 & 455 & 47 & 0.15 & 0.21 & 563 & 66 & 556 & 69 & 0.40 & 0.55 \\
\hline
\end{tabular}
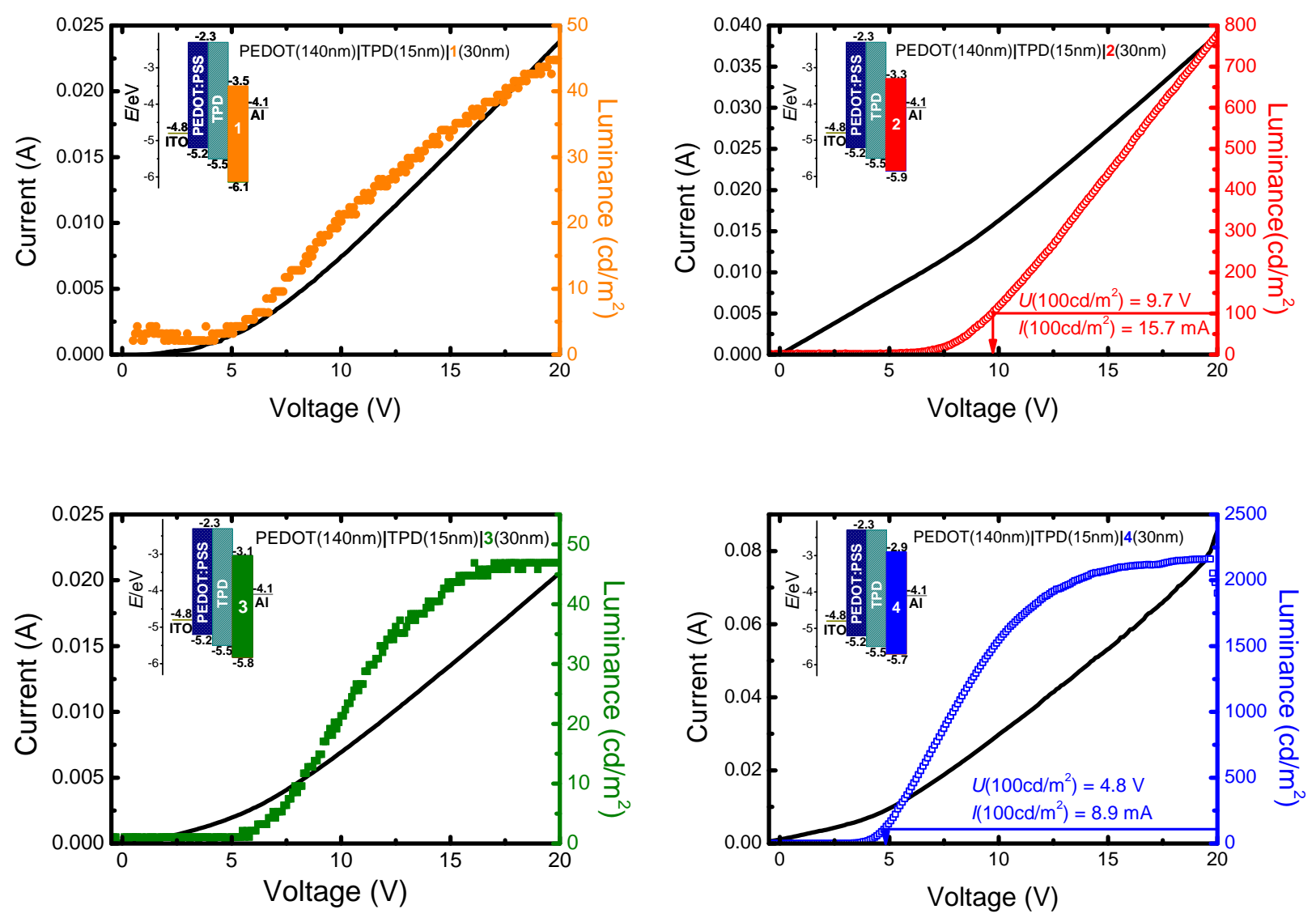

Figure 10: Current-voltage (black lines) and luminance-voltage (colored symbols) characteristics of OLEDs with the four different emitter materials (1: orange; 2: red; 3: green; 4: blue). The insets show the energy levels and layer sequence, including the thickness of the used materials. The voltage and current at a luminance of $L_{\mathrm{V}}=100 \mathrm{~cd} / \mathrm{m}^{2}\left(U\left(100 \mathrm{~cd} / \mathrm{m}^{2}\right)\right.$; $\left.I\left(100 \mathrm{~cd} / \mathrm{m}^{2}\right)\right)$ of the OLEDs with the ortho-compounds are indicated by a red and blue arrow, respectively.

The optoelectronic properties of the studied OLEDs are shown in Fig. 10 in the form of 
current-voltage and luminance-voltage diagrams, and summarized in Table 4. The insets depict the layer sequence and thickness as well as the relevant energy levels. All compounds can function as emitter layer in an OLED. However, considerable differences can be observed in terms of performance. Both OLEDs with the peri-compounds (1 \& $\mathbf{3})$ as emitter layer only achieved a maximum luminance of $L_{\mathrm{V}, \max } \approx 45 \mathrm{~cd} / \mathrm{m}^{2}$. In stark contrast, the OLED with compound 2 as emitter layer reached a maximum luminance of $L_{\mathrm{V}, \max } \approx 778 \mathrm{~cd} / \mathrm{m}^{2}$ and the OLED with compound 4 as emitter a maximum luminance of up to $L_{\mathrm{V}, \max } \approx 2165 \mathrm{~cd} / \mathrm{m}^{2}$. These two OLEDs with the ortho-emitters had a luminance of $L_{\mathrm{V}}=100 \mathrm{~cd} / \mathrm{m}^{2}$ at voltages of $U_{\mathbf{2}}\left(100 \mathrm{~cd} / \mathrm{m}^{2}\right)=9.7 \mathrm{~V}$ and $U_{\mathbf{4}}\left(100 \mathrm{~cd} / \mathrm{m}^{2}\right)=4.8 \mathrm{~V}$ at currents of $I_{\mathbf{2}}\left(100 \mathrm{~cd} / \mathrm{m}^{2}\right)=15.7 \mathrm{~mA}$ and $I_{4}\left(100 \mathrm{~cd} / \mathrm{m}^{2}\right)=8.9 \mathrm{~mA}$, respectively. It should also be noted that the current-voltage characteristics of the OLEDs employing the peri-emitters resemble typical diode behavior, whereas the current-voltage characteristics of the OLEDs with the ortho-emitters show a pronounced ohmic behavior (Fig. S4). Moreover, the analysis of the differential resistance $\left(R_{\text {diff }}=\mathrm{d} U / \mathrm{d} I\right)$ shows that only the OLEDs with $1 \& \mathbf{2}$ as emitter layer have a reasonably high shunt resistance $\left(R_{\text {shunt }}=R_{\text {diff }}(0 \mathrm{~V})\right)$, while the OLEDs with $\mathbf{3} \& \mathbf{4}$ have low values for $R_{\text {shunt }}$. The series resistance $\left(R_{\text {series }}=R_{\text {diff }}(10-20 \mathrm{~V})\right)$, on the other hand is high for all OLEDs, although the ester-OLEDs show overall the lowest values. The applied voltages were corrected under the assumption that under operation, part of the applied voltage is necessary to overcome the series resistance $\left(U_{\text {cor }}=U_{\text {applied }}-I \cdot R_{\text {series }} ;\right.$ Fig. S5). This corrected voltage can then be used to calculate the electrical power that is needed to operate the "ideal" diode without the parasitic effects of the series resistance. The OLEDs with compounds $\mathbf{2}$ - 4 start to operate at similar electrical powers $\left(P_{\text {onset }} \approx 10-12 \mathrm{~mW}\right)$, whereas it was not possible to determine $P_{\text {onset }}$ for the OLED with compound 1. Of the tested emitters, only OLEDs with 4 show a saturation of the luminance. The electrical power with the highest luminance $P_{\max }$ was also measured for OLEDs with 4 (Table 4 and Fig. S5). 
Table 4: Overview of important optoelectronic parameters of the tested OLEDs.

\begin{tabular}{c|c|c|c|c|c}
\hline & $R_{\text {shunt }} / \Omega$ & $R_{\text {series }} / \Omega$ & $P_{\text {onset }} / \mathrm{W}$ & $P_{\max } / \mathrm{W}$ & $L_{\mathrm{V}, \max } / \frac{\mathrm{cd}}{\mathrm{m}^{2}}$ \\
\hline 1 & 7600 & 720 & $\mathrm{~N} / \mathrm{A}$ & $1.3 \cdot 10^{-1}$ & 45 \\
2 & $3.3 \cdot 10^{5}$ & 650 & $1.2 \cdot 10^{-2}$ & $1.3 \cdot 10^{-1}$ & 778 \\
3 & 660 & 430 & $1.0 \cdot 10^{-2}$ & $1.1 \cdot 10^{-1}$ & 47 \\
4 & 870 & 220 & $1.1 \cdot 10^{-2}$ & $3.0 \cdot 10^{-1}$ & 2165 \\
\hline
\end{tabular}

Overall, as evidenced by the not ideal values for the shunt and series resistance, the tested OLEDs can be further improved by optimizing the manufacturing process, increasing the injection, and transport of charge carriers. Nonetheless, the differences in performance between the ortho- and peri-compounds as emitter material in OLEDs are outstanding. One avenue for future research is testing the hypothesis that the increased performance of the ortho-emitters in comparison to their peri-counterparts might be caused by the aggregation of the molecules in a slip-stacked arrangement in thin films. ${ }^{34}$ Such a molecular orientation has been described as advantageous, as it still offers good $\pi$-stacking, while also mitigating negative effects such as H-aggregation or excimer formation - processes that have been described as loss mechanisms in organic semiconductors. ${ }^{48-50}$

\section{Conclusions}

The marked red shifts of the absorption of the imides versus the esters and of the orthoversus the peri-imide, as well as the less prominent inverse shift between the esters, were corroborated by quantum chemical calculations. With the peri-ester as an example, it was shown that the reproduction of the fine structure for the lowest energy absorption band requires to take vibronic effects into account and that this band is composed of the absorption of two excited states. It could also be verified that the lowest energy absorption involves orbitals that are "perylene"-like, although small deviations in the shape of the orbitals can be observed for the ortho-compounds owing to their bent cores. Regarding the strong absorption at shorter wavelengths $(300-350 \mathrm{~nm})$ of the investigated compounds, it was found that 
"coronene"-like orbitals are involved with the exception of the ortho-imide.

Furthermore, working OLEDs could be fabricated for all compounds and thermal evaporation in a vacuum could be employed, although some degradation was observed for compound $\mathbf{3}$ as evidenced by new absorption peaks attributed to the formation of anhydrides. Optoelectronic characterization showed significant differences in performance between the OLEDs with periand ortho-substituted emitters, where the ortho-imide OLEDs exhibited 17 times and the ortho-ester OLEDs up to 57 times higher luminance than their peri-substituted counterparts. Therefore, future studies will focus on elucidating the underlying reasons for these noteworthy differences in performance.

\section{Acknowledgement}

J. V. and C. W. contributed equally to this work. J. V. acknowledges funding by the Alexander-von-Humboldt-Stiftung via a Feodor-Lynen-fellowship. C. W. acknowledges funding by the German Research Foundation (DFG) via a research scholarship (reference number: WI 4853/1-1). S. S. is supported by the DFG Heisenberg Programme (No. 270619725) and DFG project SCHU 1980/13. The quantum chemical calculations were performed on resources provided by the Paderborn Center for Parallel Computing $\left(\mathrm{PC}^{2}\right)$.

\section{Supporting Information Available}

The following files are available free of charge.

- Supplementary Information: Additional UV-vis, fluorescence and electroluminescence spectra, as well as optoelectronic characterization and additional results of quantum chemical calculations.

This material is available free of charge via the Internet at http://pubs.acs.org/. 


\section{References}

(1) Tang, C. W.; VanSlyke, S. A. Organic Electroluminescent Diodes. Appl. Phys. Lett. 1987, 51, 913-915.

(2) Burroughes, J. H.; Bradley, D. D. C.; Brown, A. R.; Marks, R. N.; Mackay, K.; Friend, R. H.; Burns, P. L.; Holmes, A. B. Light-emitting Diodes Based on Conjugated Polymers. Nature 1990, 347, 539-541.

(3) Fyfe, D. LED Technology: Organic Displays Come of Age. Nat. Photonics 2009, 3, $453-455$.

(4) Mazzio, K. A.; Luscombe, C. K. The Future of Organic Photovoltaics. Chem. Soc. Rev. 2015, 44, 78-90.

(5) Sirringhaus, H. 25th Anniversary Article: Organic Field-Effect Transistors: The Path Beyond Amorphous Silicon. Adv. Mater. 2014, 26, 1319-1335.

(6) Vollbrecht, J.; Oechsle, P.; Stepen, A.; Hoffmann, F.; Paradies, J.; Meyers, T.; Hilleringmann, U.; Schmidtke, J.; Kitzerow, H. Liquid Crystalline Dithienothiophene Derivatives for Organic Electronics. Org. Electron. 2018, 61, 266-275.

(7) Ji, D.; Jiang, L.; Cai, X.; Dong, H.; Meng, Q.; Tian, G.; Wu, D.; Li, J.; Hu, W. Large Scale, Flexible Organic Transistor Arrays and Circuits Based on Polyimide Materials. Org. Electron. 2013, 14, 2528-2533.

(8) Torsi, L.; Magliulo, M.; Manoli, K.; Palazzo, G. Organic Field-effect Transistor Sensors: A Tutorial Review. Chem. Soc. Rev. 2013, 42, 8612-8628.

(9) Garnier, F.; Hajlaoui, R.; Yassar, A.; Srivastava, P. All-polymer Field-effect Transistor Realized by Printing Techniques. Science 1994, 265, 1684-1686.

(10) Sasabe, H.; Kido, J. Development of High Performance OLEDs for General Lighting. J. Mater. Chem. C 2013, 1, 1699-1707. 
(11) Forrest, S. R. Ultrathin Organic Films Grown by Organic Molecular Beam Deposition and Related Techniques. Chem. Rev. 1997, 97, 1793-1896.

(12) Weil, T.; Vosch, T.; Hofkens, J.; Peneva, K.; Müllen, K. The Rylene Colorant Family âĂ $\breve{T}$ Tailored Nanoemitters for Photonics Research and Applications. Angew. Chem., Int. Ed. 2010, 49, 9068-9093.

(13) Wang, L.; Cui, Q.; Chen, X.-F.; Li, Y.; Li, Z.-Q.; Wang, D.; Yang, H. Novel Electric Responsive Columnar Liquid Crystals based on Perylene Tetra sec-alkyl Ester Derivatives. Aust. J. Chem. 2013, 66, 692-700.

(14) Jiang, Y.; Lu, L.; Yang, M.; Zhan, C.; Xie, Z.; Verpoort, F.; Xiao, S. Taking the Place of Perylene Diimide: Perylene Tetracarboxylic Tetraester as a Building Block for Polymeric Acceptors to Achieve Higher Open Circuit Voltage in All-polymer Bulk Heterojunction Solar Cells. Polym. Chem. 2013, 4, 5612-5620.

(15) Gupta, R. K.; Pradhan, B.; Pathak, S. K.; Gupta, M.; Pal, S. K.; Ammathnadu Sudhakar, A. Perylo [1, 12-b, c, d] Thiophene Tetraesters: A New Class of Luminescent Columnar Liquid Crystals. Langmuir 2015, 31, 8092-8100.

(16) Avlasevich, Y.; Li, C.; Müllen, K. Synthesis and Applications of Core-enlarged Perylene Dyes. J. Mater. Chem. 2010, 20, 3814-3826.

(17) Lütke Eversloh, C.; Li, C.; Müllen, K. Core-extended Perylene Tetracarboxdiimides: The Homologous Series of Coronene Tetracarboxdiimides. Org. Lett. 2011, 13, 41484150.

(18) Vollbrecht, J.; Bock, H.; Wiebeler, C.; Schumacher, S.; Kitzerow, H. Polycyclic Aromatic Hydrocarbons Obtained by Lateral Core Extension of Mesogenic Perylenes: Absorption and Optoelectronic Properties. Chem. - Eur. J. 2014, 20, 12026-12031. 
(19) Eccher, J.; Zajaczkowski, W.; Faria, G. C.; Bock, H.; Von Seggern, H.; Pisula, W.; Bechtold, I. H. Thermal Evaporation versus Spin-Coating: Electrical Performance in Columnar Liquid Crystal OLEDs. ACS Appl. Mater. Interfaces 2015, 7, 16374-16381.

(20) Vollbrecht, J.; Wiebeler, C.; Schumacher, S.; Bock, H.; Kitzerow, H. Enhanced Columnar Mesophase Range Through Distortions in Arene Cores. Mol. Cryst. Liq. Cryst. 2017, 646, 66-73.

(21) Vollbrecht, J.; Stepen, A.; Nolkemper, K.; Keuker-Baumann, S.; Kitzerow, H. Blends of Two Perylene Derivatives: Mesogenic Properties and Application As Emitter Materials in OLEDs. Polym. Sci., Ser. C 2018, 60, 48-54.

(22) McCulloch, I.; Heeney, M.; Bailey, C.; Genevicius, K.; MacDonald, I.; Shkunov, M.; Sparrowe, D.; Tierney, S.; Wagner, R.; Zhang, W. et al. Liquid-crystalline Semiconducting Polymers with High Charge-carrier Mobility. Nat. Mater. 2006, 5, 328-333.

(23) Pisula, W.; Zorn, M.; Chang, J. Y.; Müllen, K.; Zentel, R. Liquid Crystalline Ordering and Charge Transport in Semiconducting Materials. Macromol. Rapid Commun. 2009, 30, 1179-1202.

(24) Hassheider, T.; Benning, S. A.; Kitzerow, H.-S.; Achard, M.-F.; Bock, H. ColorTuned Electroluminescence from Columnar Liquid Crystalline Alkyl Arenecarboxylates. Angew. Chem., Int. Ed. 2001, 40, 2060-2063.

(25) O’Neill, M.; Kelly, S. M. Liquid Crystals for Charge Transport, Luminescence, and Photonics. Adv. Mater. 2003, 15, 1135-1146.

(26) Kasdorf, O.; Vollbrecht, J.; Ohms, B.; Hilleringmann, U.; Bock, H.; Kitzerow, H.S. Enhanced Organic Light-emitting Diode Based on a Columnar Liquid Crystal by Integration in a Microresonator. Int. J. Energy Res. 2014, 38, 452-458. 
(27) Meyers, T.; Vollbrecht, J.; Vidor, F.; Reker, J.; Kitzerow, H.-S.; Hilleringmann, U. Organic Thin-Film Transistors for AMOLED Applications. MikroSystemTechnik 2017; Congress; Proceedings of. 2017; pp 1-4.

(28) Li, C.; Wonneberger, H. Perylene Imides for Organic Photovoltaics: Yesterday, Today, and Tomorrow. Adv. Mater. 2012, 24, 613-636.

(29) Peurifoy, S. R.; Guzman, C. X.; Braunschweig, A. B. Topology, Assembly, and Electronics: Three Pillars for Designing Supramolecular Polymers with Emergent Optoelectronic Behavior. Polym. Chem. 2015, 6, 5529-5539.

(30) Wu, W.; Liu, Y.; Zhu, D. $\pi$-Conjugated Molecules with Fused Rings for Organic Fieldeffect Transistors: Design, Synthesis and Applications. Chem. Soc. Rev. 2010, 39, 1489-1502.

(31) Sergeyev, S.; Pisula, W.; Geerts, Y. H. Discotic Liquid Crystals: A New Generation of Organic Semiconductors. Chem. Soc. Rev. 2007, 36, 1902-1929.

(32) Funahashi, M. Nanostructured Liquid-Crystalline Semiconductors-A New Approach to Soft Matter Electronics. J. Mater. Chem. C 2014, 2, 7451-7459.

(33) Cuerva, C.; Campo, J. A.; Ovejero, P.; Torres, M. R.; Oliveira, E.; Santos, S. M.; Lodeiro, C.; Cano, M. Columnar Discotic Pt (II) Metallomesogens as Luminescence Multifunctional Materials with Chemo and Thermosensor Abilities. J. Mater. Chem. C 2014, 2, 9167-9181.

(34) Ferreira, M.; Moreira, T. S.; Cristiano, R.; Gallardo, H.; Bentaleb, A.; Dechambenoit, P.; Hillard, E. A.; Durola, F.; Bock, H. Isomeric Column-Forming Esters and Imides with Varying Curvatures of the Aromatic Plane. Chem. - Eur. J. 2018, 24, 2214-2223. 
(35) Vollbrecht, J.; Blazy, S.; Dierks, P.; Peurifoy, S.; Bock, H.; Kitzerow, H. Electroluminescent and Optoelectronic Properties of OLEDs with Bay-Extended, Distorted Perylene Esters as Emitter Materials. ChemPhysChem 2017, 18, 2024-2032.

(36) Dennington, R.; Keith, T.; Millam, J. GaussView Version 5.0.9. Semichem Inc. Shawnee Mission KS 2009.

(37) Vollbrecht, J.; Wiebeler, C.; Neuba, A.; Bock, H.; Schumacher, S.; Kitzerow, H. Bayextended, Distorted Perylene Esters Showing Visible Luminescence after Ultraviolet Excitation: Photophysical and Electrochemical Analysis. J. Phys. Chem. C 2016, 120, 7839-7848.

(38) Frisch, M. J.; Trucks, G. W.; Schlegel, H. B.; Scuseria, G. E.; Robb, M. A.; Cheeseman, J. R.; Scalmani, G.; Barone, V.; Mennucci, B.; Petersson, G. A. et al. Gaussian 09 Revision D.01. Gaussian Inc. Wallingford CT 2009.

(39) Perdew, J. P.; Burke, K.; Ernzerhof, M. Generalized Gradient Approximation Made Simple. Phys. Rev. Lett. 1996, 77, 3865-3868.

(40) Adamo, C.; Barone, V. Toward Reliable Density Functional Methods without Adjustable Parameters: The PBE0 Model. J. Chem. Phys. 1999, 110, 6158-6170.

(41) Hehre, W. J.; Ditchfield, R.; Pople, J. A. Self-Consistent Molecular Orbital Methods. XII. Further Extensions of Gaussian-Type Basis Sets for Use in Molecular Orbital Studies of Organic Molecules. J. Chem. Phys. 1972, 56, 2257-2261.

(42) Chen, J.-H.; He, L.-M.; Wang, R. L. Connection of DFT Molecular Orbital Eigenvalues with the Observable Oxidation Potentials/Oxidation Energies. J. Phys. Chem. A 2013, $117,5132-5139$.

(43) Martin, R. L. Natural Transition Orbitals. J. Chem. Phys. 2003, 118, 4775-4777. 
(44) Plasser, F. TheoDORE 1.6: a package for theoretical density, orbital relaxation, and exciton analysis, available from: http://theodore-qc.sourceforge.net. (Accessed: 04.11.2018).

(45) Plasser, F.; Lischka, H. Analysis of Excitonic and Charge Transfer Interactions from Quantum Chemical Calculations. J. Chem. Theory Comput. 2012, 8, 2777-2789.

(46) Jmol: An Open-Source Java Viewer for Chemical Structures in 3D, http://www.jmol.org/. (Accessed: 04.11.2018).

(47) Barone, V.; Bloino, J.; Biczysko, M.; Santoro, F. Fully Integrated Approach to Compute Vibrationally Resolved Optical Spectra: From Small Molecules to Macrosystems. J. Chem. Theory Comput. 2009, 5, 540-554.

(48) Vollbrecht, J. Excimers in Organic Electronics. New J. Chem. 2018, 42, 11249-11254.

(49) Margulies, E. A.; Shoer, L. E.; Eaton, S. W.; Wasielewski, M. R. Excimer Formation in Cofacial and Slip-stacked Perylene-3, 4: 9, 10-bis (Dicarboximide) Dimers on a Redoxinactive Triptycene Scaffold. Phys. Chem. Chem. Phys. 2014, 16, 23735-23742.

(50) Hartnett, P. E.; Timalsina, A.; Matte, H. S. S. R.; Zhou, N.; Guo, X.; Zhao, W.; Facchetti, A.; Chang, R. P. H.; Hersam, M. C.; Wasielewski, M. R. et al. Slip-stacked Perylenediimides as an Alternative Strategy for High Efficiency Nonfullerene Acceptors in Organic Photovoltaics. J. Am. Chem. Soc. 2014, 136, 16345-16356. 
Graphical TOC Entry

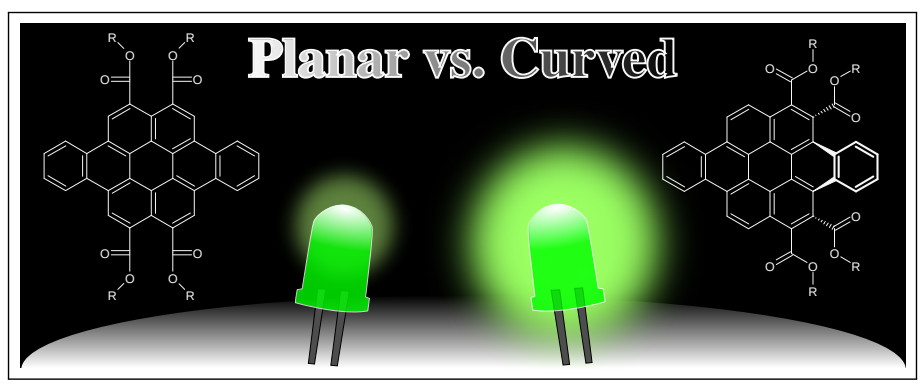

